\title{
PRODUCTION OF DIRECTLY COMPRESSIBLE EXCIPIENTS WITH MANNITOL BY WET GRANULATION: RHEOLOGICAL, COMPRESSIBILITY AND COMPACTIBILITY CHARACTERIZATION
}

\author{
OSWALDO CASTAÑEDA HERNÁNDEZ ${ }^{1}$, EFRÉN HERNÁNDEZ BALTAZAR ${ }^{2}$, ENRIQUE \\ AMADOR GONZÁLEZ ${ }^{3}$, LUZ MARÍA MELGOZA CONTRERAS ${ }^{1 *}$ \\ ${ }^{1}$ Universidad Autónoma Metropolitana, Departamento de Sistemas Biológicos \& Maestría en Ciencias Farmacéuticas, \\ Calzada del Hueso No. 1100, Villa Quietud, Coyoacán, Ciudad de México, Estados Unidos Mexicanos \\ ${ }^{2}$ Facultad de Farmacia, Universidad Autónoma del Estado de Morelos, Cuernavaca, Morelos, Estados Unidos Mexicanos \\ ${ }^{3}$ Facultad de Química, Universidad Nacional Autónoma de México, Coyoacán, Ciudad de México, Estados Unidos Mexicanos
}

*corresponding author: Imelgoza@correo.xoc.uam.mx

Manuscript received: March 2018

\begin{abstract}
The purpose of this research was to produce co-processed excipients using mannitol as base material with some of the most used binders: potato, maize pre-gelatinized starch, and K-25, K-29/32, K-90 povidone. Mannitol, one commercial basedmannitol product, and the produced materials were characterized by their particle size distribution, Carr's index, Hausner ratio, angle of repose, powder flow, and moisture content. Heckel analysis, compactibility profiles, and RyshkewitchDuckworth analysis were also evaluated. It is concluded that co-processing mannitol enhances flow, compressibility, and compactibility properties of the materials. Heckel analysis showed a decreased yield pressure $\left(P_{y}\right)$ value for the co-processed materials; while a 10-times increment in mechanical resistance of co-processed materials was observed in compactibility profiles in comparison with mannitol tablets. Ryshkewitch-Duckworth analysis allowed the calculation of the bonding capacity, which in some cases was similar to ductile materials as microcrystalline cellulose.
\end{abstract}

\section{Rezumat}

Scopul acestei lucrări a fost obținerea de excipienți co-procesați pornind de la manitol, alături de lianți precum: cartof, poromb, amidon pre-gelatinizat şi povidonă K-25, K-29/32, K-90. Manitolul și ceilalți excipienți au fost caracterizați prin distribuția mărimii particulelor, indexul Carr, raportul Hausner, capacitatea de curgere şi umiditatea relativă. Analiza Heckel, pofilele de compactibilitate și analiza Ryshkewitch-Duckworth au fost, de asemenea, evaluate. Co-procesarea manitolului îmbunătățește profilele de curgere, compresibilitate și compactibilitate ale materialelor. Analiza Heckel a arătat o scădere a valorii presiuni $\left(P_{y}\right)$ pentru materialele co-procesate; a fost observată o creștere de 10 ori a rezistenței mecanice pentru materialele co-procesate pe baza pofilelor de compactibilitate raportate la comprimatele cu manitol. Analiza RyshkewitchDuckworth a permis calcularea capacității de legare, care în unele cazuri a fost similară cu cea a celulozei microcristaline.

Keywords: co-processed excipients, mannitol, rheological characterization, compressibility and compactibility

\section{Introduction}

Historically, oral route has been the most often used route of prescription and administration of medicines; tablets are considered the pharmaceutical dosage form of choice for patients and pharmaceutical companies because they are cheap and easy to be administered [1]. There are three methods for their production: wet granulation (WG), dry granulation (DG) and direct compression (DC), their advantages and disadvantages are well documented for each one [2-4]. Granulation is a process of particle enlargement by means of agglomeration of individual particles, which at a certain point can be identified. The main difference between WG and DG is that the first requires the presence of a liquid to agglomerate the particles [5]. DC involves few processing steps, less equipment and time of production and therefore, permits economical and energy savings. However, DC is highly impacted by properties of the excipients used, e.g. flow, compressibility, compactibility, and dilution potential; which will allow good die filling, better content uniformity, and less weight variation.

About $80 \%$ of marketed tablets are produced by WG despite involving a larger number of operation stages, addition and removal of water, and stability related problems for thermolabile drugs and those that can be susceptible of hydrolysis [6]. It has been estimated that less of $20 \%$ of pharmaceutical materials can be directly compressed and that the rest of them lack good flow properties, cohesion, and lubrication to produce tablets by DC, which means that not always the excipients have the ideal performance properties to allow certain products to be developed or manufactured adequately [7, 8]. For such reasons, combinations of excipients are used and they are classified into two 
broad groups: physical mixtures and co-processed excipients. The co-processing consists in the interaction of two or more excipients at sub-particle level; it produces an excipient with improved functionality and masking the undesirable properties when some of the components have them [9]. Co-processing is a cost-effective method of providing high functionality materials, and its principal advantage is the absence of rigorous toxicological and safety studies as those in new chemical entities designed to be used as excipients $[10,11]$. At this respect, the most common coprocessing strategies are spray-drying, granulation, melt extrusion and milling.

D-mannitol is a polyol and isomer carbohydrate of sorbitol. It is a crystalline odourless with sweet flavour powder which results refreshing for the mouth; therefore, is mainly used in pharmaceutical solid dosage forms as a diluent excipient (10 - 90\% w/w) in chewing, paediatric and geriatric, and orally disintegrating tablets $[12,13]$. Mannitol presents various polymorphs [14], but the commercial and more stable form ( $\beta$ polymorph) is characterized by having poor compressibility and compactibility properties, and insufficient disintegration [15-20]. Recently, the pharmaceutical industry has put great interest in mannitol due to its chemical stability, water-solubility, and low hygroscopicity [21]; however, crystalline mannitol is very friable, leading to the formation of fine particles that decrease its flow properties.

In addition, there are a few commercial co-processed (CP) excipients based on mannitol for DC e.g., Parteck ${ }^{\circledR}$ ODT (mannitol and croscarmellose sodium, produced by spray-drying) Pearlitol ${ }^{\circledR}$ Flash (mannitol and starch, produced by WG), Disintequick ${ }^{\mathrm{TM}}$ ODT (mannitol, lactose, crospovidone, and dextrose monohydrate, produced by freeze-drying), Compressol ${ }^{\mathrm{TM}} \mathrm{SM}$ (mannitol and sorbitol, produced by WG), Ludiflash ${ }^{\circledR}$ (mannitol, crospovidone and polyvinyl acetate, produced by WG), F-MELT ${ }^{\circledR}$ Type C (mannitol, xylitol, microcrystalline cellulose, crospovidone, and dibasic calcium phosphate anhydrous, produced by spray-drying), and F-MELT $^{\circledR}$ Type M (mannitol, xylitol, microcrystalline cellulose, crospovidone and magnesium aluminometasilicate, produced by spray-drying).

The aim of this study was to develop co-processed excipients using mannitol as a base excipient in combination with some of the most common polymers used at the pharmaceutical industry: starch (potato, corn and pregelatinized) and povidone (K-25, K-29/32 y K-90) by wet granulation in fluid bed dryer. Classify them according to their rheological characterization, compressibility and compactibility properties with mathematical models, compare the developed products with mannitol alone, their physical mixture (only for the best materials), and a commercial product (Pearlitol ${ }^{\circledR}$ Flash). According to the literature, there are few reports that deal with co-processing of mannitol and none of them has employed the proposed polymers and process treated by this research [8, 22-26].

\section{Materials and Methods}

\section{Materials}

The materials used were crystalline D-Mannitol ( $\beta$ polymorph, Merck Millipore, Germany), corn starch (Química Barsa, México), potato starch (Química Meyer, México), pregelatinized starch (Starch $1500^{\circledR}$, Colorcon, USA), povidone K-25, K-29/32 and K-90 (Plasdone $^{\mathrm{TM}}$, Ashland, USA), deionized water (Aguam, Mexico), Pearlitol ${ }^{\circledR}$ Flash (Roquette, France), and magnesium stearate (Merck Millipore, Germany).

Production of co-processed excipients

The co-processed materials were prepared using a fraction of mannitol's particle size between 40 - 100 $\mu \mathrm{m}$. The dispersions of binding agents (starches and povidones) were prepared at $10 \% \mathrm{w} / \mathrm{w}$ by mixing $17.65 \mathrm{~g}$ of binder in deionized water $(158.9 \mathrm{~g})$ under constant stirring with an overhead stirrer (Caframo BDC 2002). The co-processing was performed in a fluid bed dryer (Aeromatic-Fielder Strea 1, Gea Pharma) by continuous spraying of the binder solutions to mannitol and drying at the same time, using a peristaltic pump (Watson-Marlow CSI-323), $100 \mathrm{~g}$ of mannitol were placed in the conical chamber. Mannitol was preheated for 5 minutes, once the chamber reached $50^{\circ} \mathrm{C}$ the spraying of the binder solutions started. Binder solutions were sprayed at a rate near to $4-6 \mathrm{~g} / \mathrm{min}$ with an atomization pressure of 1.0 bar using a centred top-spray nozzle. The fluidizing air velocity was nearly to $0.95 \mathrm{~m} / \mathrm{s}$, inlet and outlet temperatures were 30 - 35 and $25^{\circ} \mathrm{C}$ respectively. The environmental conditions were $20-25^{\circ} \mathrm{C}$ and relative humidity of $40-55 \%$. Corn starch (CS) and potato starch (PS) dispersions were prepared with hot water. Triplicate performed each batch; each one of them had a time of $40-50 \mathrm{~min}$. Preparation of physical mixtures

Physical mixtures were prepared using the same proportions of each excipient (85:15\% of Mannitol: Polymer respectively, it means $100 \mathrm{~g}$ of mannitol and $17.65 \mathrm{~g}$ of the polymers) in a V blender $(0.5 \mathrm{~L})$ coupled to an universal gear (Erweka ${ }^{\circledR}$ AR 402) during $5 \mathrm{~min}$ at $10 \mathrm{rpm}$ in order to evaluate the influence of the co-processing in the materials' performance. Physical mixtures were produced only for the best co-processed excipients.

Particle size distribution

Particle size distribution was determined in a vibratory sieve shaker (Restch AS 200) with test sieves mesh $30,40,50,60,80,100,120,140,200,250,270$ and 400 , for $5 \mathrm{~min}$ each batch at $0.5 \mathrm{~mm}$ amplitude of oscillation [27]. The rheological properties of the selected fractions of particle size distribution were evaluated as described below. 
Rheological characterization

Bulk and tapped density determination. Bulk density and tapped density $\left(\rho_{\mathrm{b}}\right.$ and $\left.\rho_{\mathrm{t}}\right)$ were manually determined by the measuring cylinder method $(100 \mathrm{~mL}$ graduated cylinder) [28]. The $\rho_{b}$ represents the quantity of powder necessary to fill the $100 \mathrm{~mL}$ cylinder without tapping the sample, whereas $\rho_{\mathrm{t}}$ represents the final volume registered once all particles stop the rearrangement caused by the mechanical compaction of the materials. Carr's index (CI) or compressibility percentage and Hauser's ratio (HR) were calculated using equation 1 and 2 , respectively.

$$
\begin{gathered}
C I=\frac{\rho_{\mathrm{t}}-\rho_{b}}{\rho_{t}} \times 100 \\
H R=\frac{\rho_{t}}{\rho_{b}},
\end{gathered}
$$

Angle of repose and flow rate. The angle of repose (AR) was determined by the funnel method; each material was poured into the funnel and then allowed the sample to flow through it and reach a flat surface. A powder cone was formed and measured relative to the horizontal, where $h$ represents the height and $r$ the ratio of the basis of the cone (equation 3). To calculate flow rate $\left(F_{r}\right)$ a flowability tester $\left(\right.$ Erweka $^{\circledR}$ SUM 22) with a stainless steel of $10 \mathrm{~mm}$ diameter outlet nozzle was used, this parameter represents the quantity of sample per unit of time (g/s) (equation 4).

$$
\begin{gathered}
A R=\tan ^{-1}\left(\frac{h}{r}\right), \\
F_{r}=\frac{g}{s},
\end{gathered}
$$

Moisture content. Moisture content (\% MC) was measured in a moisture analyser (Ohaus ${ }^{\circledR}$ MB45), with a heating ramp of $10^{\circ} \mathrm{C} / \mathrm{min}$ for $10 \mathrm{~min}$ until reaching a $100^{\circ} \mathrm{C}$ final temperature.

Photographs of mannitol and co-processed materials. The photographs of the raw mannitol and co-processed materials were obtained using an Olympus SZ51 stereomicroscope (Olympus Corporation, PA, USA). The samples were placed and spread in the shade plate for microscope imaging.

Heckel analysis and tensile strength vs compaction pressure plots

Tablets were compressed in a hydraulic press (Carver 3012) using $13 \mathrm{~mm}$ diameter flat-faced punches, applying a compaction pressure of 7 to $282 \mathrm{MPa}$ and a time of compression of $5 \mathrm{~s}$. Quantity of $500 \mathrm{mg}$ of each material were weighted for a single tablet. Relative density $\left(\rho_{\text {rel }}\right)$ was determined by the ratio of bulk density of the tablet $\left(\rho_{b}\right)$ and true density of powder $\left(\rho_{t}\right)$; which was calculated from the measurement of tablets obtained at a compaction pressure of 650 MPa (equation 5). The material's deformation behaviour was evaluated through Heckel equation, where $P_{\text {compac }}$ is the compaction pressure, $K$ is the slope known as Heckel constant, and the inverse of $K$ is the yield pressure $\left(P_{y}\right)$. Additionally, the intercept $A$ is related with $\rho_{\text {rel }}$ (equations 6,7 and 8, respectively). The slope was obtained from the linear portion of the plot, and it was selected with the minimum squares' method.

$$
\begin{gathered}
\rho_{r e l}=\frac{\rho_{b}}{\rho_{T}} \\
\ln \left(\frac{1}{1-\rho_{\text {rel }}}\right)=K P_{\text {compac }}+A \\
K=\frac{1}{P_{y}} \\
\rho_{\text {rel }}=1-e^{-A},
\end{gathered}
$$

Dimensions of tablets were measured $24 \mathrm{~h}$ after compression using an electronic Vernier and weighted with an accuracy of $0.1 \mathrm{mg}$ (Mettler Toledo AB204$\mathrm{S})$. Three tablets were evaluated for each compaction pressure.

Such tablets were used to evaluate the diametrical crushing force (tablet hardness tester, Pharma Alliance PAH-01) and thus tensile strength $\left(\sigma_{T}\right) v s$ compaction pressure $\left(P_{\text {compac }}\right)$ plots were evaluated according to equation 9 , where $F$ is the breaking force, $d$ is the diameter of the tablet, and $h$ is the thickness of the tablet [29].

$$
\sigma_{T}=\frac{2 F}{\pi d h},
$$

Ryshkewitch-Duckworth model

The tensile strength and porosity data of the compacts with different materials were fitted according to the Ryskewitch-Duckworth relation (Equation 10):

$$
\operatorname{Ln} \frac{\sigma_{T}}{\sigma_{T_{0}}}=-k \varepsilon
$$

in which $\sigma_{T}$ is the tensile strength of the tablet, $\sigma_{T 0}$ the tensile strength at zero porosity, $\varepsilon$ the compact porosity obtained with the relative density relation (equation 11), and $k$ a constant of the model. The values of $k$ and $\sigma_{T O}$ were obtained by linear regression analysis.

$$
\varepsilon=\left(1-\frac{\rho_{b}}{\rho_{T}}\right),
$$

Statistical analysis

A normality test was performed for each parameter in Heckel and Ryshkewitch-Duckworth analyses in order to know the statistical test to be used for establishing whether it was statistically significant difference between our materials and the base excipient. All the comparisons used mannitol as control group.

For Heckel parameters $\left(K, P_{y}\right.$ and $\left.A ; \mathrm{n}=3\right)$, Dunnett by multiple comparisons test was performed; while 
multivariate analysis of variance (MANOVA; $n=30$ for each material) was used to evaluate the behaviour during densification process.

Regarding to the Ryshkewitch-Duckworth analysis, its parameters were evaluated with a Kruskal-Wallis test for $\sigma_{T O}$ and a Dunnett by multiple comparisons for $k$; furthermore, increasing $\sigma_{T O}$ as function of porosity $(\varepsilon)$ was evaluated with a MANOVA test.

\section{Results and Discussion}

\section{Particle size distribution}

Particle size is an important parameter that affects the properties related to a material's performance and therefore the final properties of a tablet such as hardness, friability, disintegration time, dissolution and content uniformity [30-32]. The last two are directly related to the quantity of pharmaceutical active ingredient in the pharmaceutical dosage form. Figure 1 shows the particle size distribution of mannitol, the coprocessed excipients, and Pearlitol ${ }^{\circledR}$ Flash.

In the particle size distribution plot corresponding to mannitol, two populations (binomial and asymmetrical distribution) at 40 and $100 \mu \mathrm{m}$ can be observed, both account for about $73 \%$ of the total distribution; they were recovered for co-processed production and for mannitol's rheological characterization.

According to the literature, it is considered that suitable particle size for DC must be between $200-400 \mu \mathrm{m}$ [33]. In general terms, all co-processed presented a particle size into this range; materials with pregelatinized starch (PrS), potato starch (PS) and corn starch (CS) registered highest mean particle sizes (341, 315 and 314 $\mu \mathrm{m}$, respectively); while the material with povidone K-25 (PVP) presented the smaller size $(265 \mu \mathrm{m})$ (Table I). Pearlitol ${ }^{\circledR}$ Flash presented a mean particle size of $255 \mu \mathrm{m}$. In regarding to particle size curves, only the material with PVP K-29/32 presented a symmetrical distribution, while the others were asymmetrical as Pearlitol ${ }^{\circledR}$ Flash as well.

The $f$ factor represents a measurement of the distribution's amplitude and it is defined by the ratio $d_{0.9} / d_{0.1}$; the lower value of $f$ factor, the narrower the distribution, the higher homogeneity in particle size distribution will be revealed. Although the material with PVP K-25 presented the smaller mean particle sizes along with the PrS co-processed, both had the narrower distribution $(f<2.0)$ compared to materials with PS and CS which presented the wider, while Pearlitol ${ }^{\circledR}$ Flash presented an $f$ value of 2.02 . Table I summarizes the mean particle sizes, $d_{0.1}, d_{0.5}, d_{0.9}$, and $f$ for the materials.

In order to avoid discrepancies and mistakes in the rheological characterization of the co-processed excipients influenced by the particle size differences, only the fractions of particle size distribution comprehended between 200 - $400 \mu \mathrm{m}$ were taken to be evaluated. Fractions were collected after sieve analysis in each case.

Table I

Mean particle size of mannitol and co-processed excipients

\begin{tabular}{lccccc}
\hline \multicolumn{1}{c}{ Material } & $\boldsymbol{M P S}(\boldsymbol{\mu m})$ & $\boldsymbol{d}_{\boldsymbol{0 . 1}}$ & $\boldsymbol{d}_{\boldsymbol{0 . 5}}$ & $\boldsymbol{d}_{\boldsymbol{0 . 9}}$ & $\boldsymbol{f}$ \\
\hline MAN & 101 & 42.84 & 73.08 & 126.02 & 2.94 \\
MAN-PS & 315 & 98.70 & 246.96 & 396.90 & 4.02 \\
MAN-CS & 314 & 103.74 & 238.77 & 417.06 & 4.02 \\
MAN-PrS & 341 & 115.29 & 262.08 & 415.38 & 1.58 \\
MAN-PVP K-25 & 265 & 138.82 & 213.05 & 273.42 & 1.97 \\
MAN-PVP K-29/32 & 301 & 141.01 & 244.66 & 295.07 & 2.09 \\
MAN-PVP K-90 & 312 & 107.10 & 251.68 & 351.66 & 3.28 \\
Pearlitol $^{\circledR}$ Flash (PF) & 255 & 130.50 & 212.31 & 264.01 & 2.02 \\
\hline
\end{tabular}

MPS $=$ mean particle size; $\mathrm{f}=$ ratio $\mathrm{d}_{0.9} / \mathrm{d}_{0.1}$

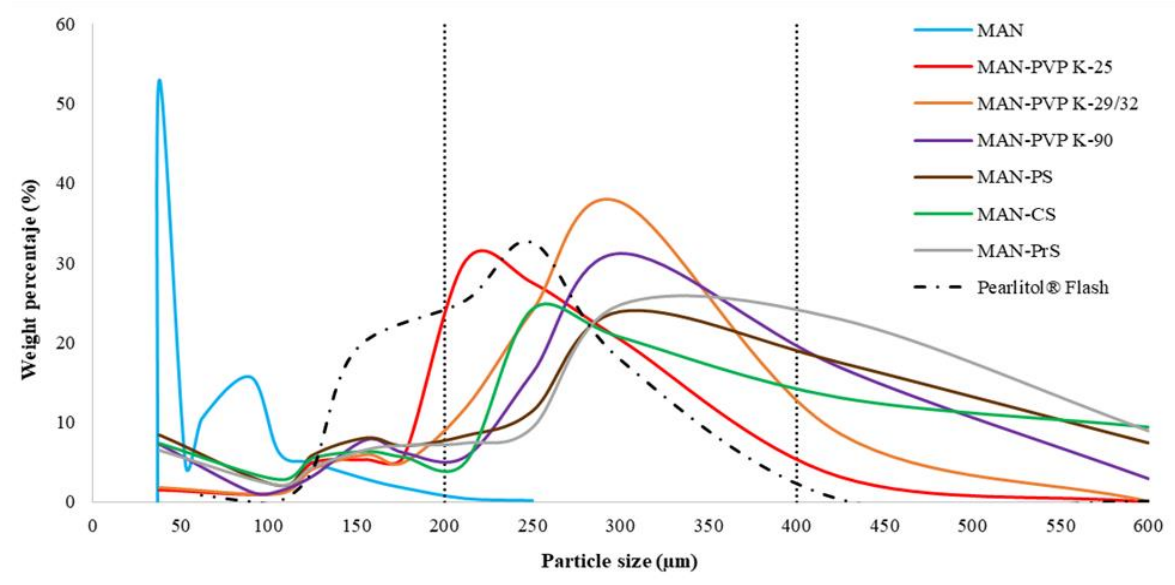

Figure 1.

Particle size distribution of mannitol, commercial product (Pearlitol ${ }^{\circledR}$ Flash, PF) and co-processed excipients 


\section{Rheological characterization}

The rheological properties of the materials are summarized in Table II. Compressibility percentage or CI is a measurement of the material's ability to reduce its volume and along with Hausner's ratio (HR), allows an assessment of inter-particulate interactions. In a free-flowing powder, the interactions are less significant and $\rho_{b}$ and $\rho_{t}$ will be present in similar values, on the contrary, in poor flowing powders interparticulate interactions are present in a high percentage

and so the difference between $\rho_{b}$ and $\rho_{t}$ [34]. At this respect, all co-processed excipients presented a $\rho_{b}$ close to $\rho_{t}$; whereas mannitol had a difference of almost twice the value of the densities for co-processed materials. In accordance with the USP criteria [35], mannitol is classified as a poor flowing and compressible material; while the rest of the materials are acceptable, or in the case of co-processed with PVP K-25 it is excellent, which presented similar and even improved Carr and Hausner index than Pearlitol ${ }^{\circledR}$ Flash.

Table II

Rheological characterization of mannitol and co-processed excipients

\begin{tabular}{|c|c|c|c|c|c|c|c|c|}
\hline Material & $\rho_{b}\left(\mathrm{~g} / \mathrm{cm}^{3}\right)$ & $\rho_{c}\left(\mathrm{~g} / \mathrm{cm}^{3}\right)$ & CI & HR & $\mathbf{A R}\left(^{\circ}\right)$ & $F_{r}(g / s)$ & $\begin{array}{c}\% \\
\mathrm{MC}\end{array}$ & $\begin{array}{c}\text { Flow } \\
\text { properties } \\
(\text { USP criteria })\end{array}$ \\
\hline MAN & $0.528 \pm 0.002$ & $0.733 \pm 0.003$ & $27.96 \pm 0.02$ & $1.38 \pm 3.3 \times 10^{-4}$ & $45.86 \pm 0.59$ & $1.41 \pm 0.38$ & 0.06 & Poor \\
\hline $\begin{array}{l}\text { MAN-PS (MAN-PS } \\
\text { physical mixture) }\end{array}$ & $\begin{array}{c}0.317 \pm 0.005 \\
(0.558)\end{array}$ & $\begin{array}{c}0.375 \pm 0.004 \\
(0.734)\end{array}$ & $\begin{array}{c}15.46 \pm 2.11 \\
(23.97)\end{array}$ & $\begin{array}{c}1.18 \pm 0.014 \\
(1.31)\end{array}$ & $\begin{array}{c}32.76 \pm 2.59 \\
(35.91)\end{array}$ & $\begin{array}{c}4.05 \pm 0.19 \\
(2.17)\end{array}$ & $\begin{array}{l}1.56 \\
(N D)\end{array}$ & $\begin{array}{c}\text { Good } \\
\text { (Passable) }\end{array}$ \\
\hline MAN-CS & $0.312 \pm 0.021$ & $0.376 \pm 0.012$ & $17.02 \pm 3.54$ & $1.20 \pm 0.019$ & $31.93 \pm 2.11$ & $4.07 \pm 0.22$ & 1.80 & Good \\
\hline MAN-PrS & $0.336 \pm 0.010$ & $0.396 \pm 0.021$ & $15.15 \pm 1.38$ & $1.18 \pm 0.029$ & $30.59 \pm 3.81$ & $3.96 \pm 0.12$ & 1.80 & Excellent \\
\hline $\begin{array}{l}\text { MAN-PVP K-25 } \\
\text { (MAN-PVP K-25 } \\
\text { physical mixture) }\end{array}$ & $\begin{array}{l}0.290 \pm 0.012 \\
(0.507)\end{array}$ & $\begin{array}{c}0.318 \pm 0.024 \\
(0.689)\end{array}$ & $\begin{array}{c}8.80 \pm 2.66 \\
26.41\end{array}$ & $\begin{array}{c}1.09 \pm 0.038 \\
(1.35)\end{array}$ & $\begin{array}{c}34.23 \pm 1.12 \\
(36.75)\end{array}$ & $\begin{array}{c}7.08 \pm 0.09 \\
(2.85)\end{array}$ & $\begin{array}{l}1.93 \\
(N D)\end{array}$ & $\begin{array}{l}\text { Excellent } \\
\text { (Poor) }\end{array}$ \\
\hline MAN-PVP K-29/32 & $0.294 \pm 0.011$ & $0.350 \pm 0.022$ & $16.00 \pm 6.01$ & $1.19 \pm 1.0 .09$ & $34.95 \pm 0.85$ & $3.68 \pm 0.37$ & 2.21 & Good \\
\hline MAN-PVP K-90 & $0.307 \pm 0.006$ & $0.349 \pm 0.010$ & $12.03 \pm 1.15$ & $1.13 \pm .014$ & $33.27 \pm 1.25$ & $3.69 \pm 0.42$ & 0.93 & Good \\
\hline Pearlitol ${ }^{\circledR}$ Flash (PF) & $0.478 \pm 0.015$ & $0.535 \pm 0.007$ & $10.65 \pm 1.89$ & $1.12 \pm 0.02$ & $23.38 \pm 2.07$ & $9.60 \pm 0.29$ & 1.78 & Excellent \\
\hline
\end{tabular}

$\mathrm{ND}=$ non determined; $\rho_{\mathrm{b}}=$ bulk density; $\rho_{\mathrm{t}}=$ tapped density; $\mathrm{CI}=$ Carr's index; $\mathrm{AR}=$ angle of repose; $\mathrm{HR}=\mathrm{Hausner}$ 's ratio; Fr $=$ flow rate; $\% \mathrm{MC}=$ percentage of moisture content

Angle of repose has been widely used for bulk powder characterization [36-38], it is also related with interparticulate friction, and therefore with powder flowability. The higher angle value, the poorer will be the flow of the material and the greater its resistance to flow. For mannitol, an angle of repose of $45.86^{\circ}$ was observed, according to the USP criteria [35] it is classified as a material with an acceptable flow, however, it just flowed after moving the sample with a spatula. For this reason, the correct classification would be a poor flowing material, while the rest of co-processed are classified as good flowing powders. It is important to say that angle of repose is not considered a robust test to determine the material flow due to the dependence in test conditions $[35,39]$; so that along with the angle it is evaluated $F_{r}$ to have additional information and realistic data of how a material flows and how its performance is during die filling before compression. Mannitol presented a $F_{r}$ of $1.41 \mathrm{~g} / \mathrm{s}$, while in the material with PVP K-25 it was observed a five-times increment compared with the base excipient. For the rest of co-processed materials, the increment was three times compared to mannitol. Pearlitol ${ }^{\circledR}$ Flash presented a minor angle in comparison with our products and a major, but nearer $F_{r}$ to MANPVP K-25.

Moisture content (MC) is another property that has an impact on material's flow. Hiestand found that moisture could influence the interaction force between solid particles and as result, it affects cohesion and friction of the materials. Furthermore, this can cause stability problems in the final pharmaceutical dosage form [40]. In this research, it was important to determine such property due to the inherent characteristics of the co-processing method which involved wetting the materials with an aqueous dispersion. The results indicated that mannitol had moisture less than $0.1 \%$ that corresponded to the low hygroscopicity and low swelling ability of this material preventing the adsorption and absorption of water [21, 41]. On the other hand, the rest of co-processed presented a moisture content near to $2 \%$. It has been suggested that as the moisture increases in a powder, the produced tablets could present less hardness due to the formation of multi-layered water, which avoids direct contact between particles [40]. Nevertheless, a dependence of tablet hardness with the moisture for certain materials has been reported; at this respect, Nokhodchi et al., [42] identified that HPMC K4M tablets increased their hardness as moisture was also increased from 0 to $14.9 \%$.

The comparison with the physical mixtures was realized only for the best materials in each case; i.e. the PVP K-25 and Pre-gelatinized Starch mixes. The results are shown between parentheses in Table II, in which an improvement of the properties with the co-processing method can be seen due to the CI, HR, and AR decreasing, in addition to an improvement in flow rate for the co-processed materials.

Heckel analysis

Figure 2 shows Heckel plots for mannitol and its coprocessed, we can observe from these plots a linear relation of $\ln \left[1 /\left(1-\rho_{\text {rel }}\right)\right]$ as a function of $P_{\text {compac }}$ between $21-211 \mathrm{MPa}$ for all the tested materials. The linear region of such plots is where yielding of the materials 
took place and densification occurred through particle's deformation, such regions were selected to analyse the model with the minimum squares regression; additionally, at low compaction pressures $(0.1-21$ $\mathrm{MPa})$ a slight curvature is observed, attributable to the displacement and rearrangement of particles during compression [43]. Table III summarizes the parameters obtained with Heckel analysis. Figure 2 shows Heckel plots for a) starches and b) povidones co-processed excipients.

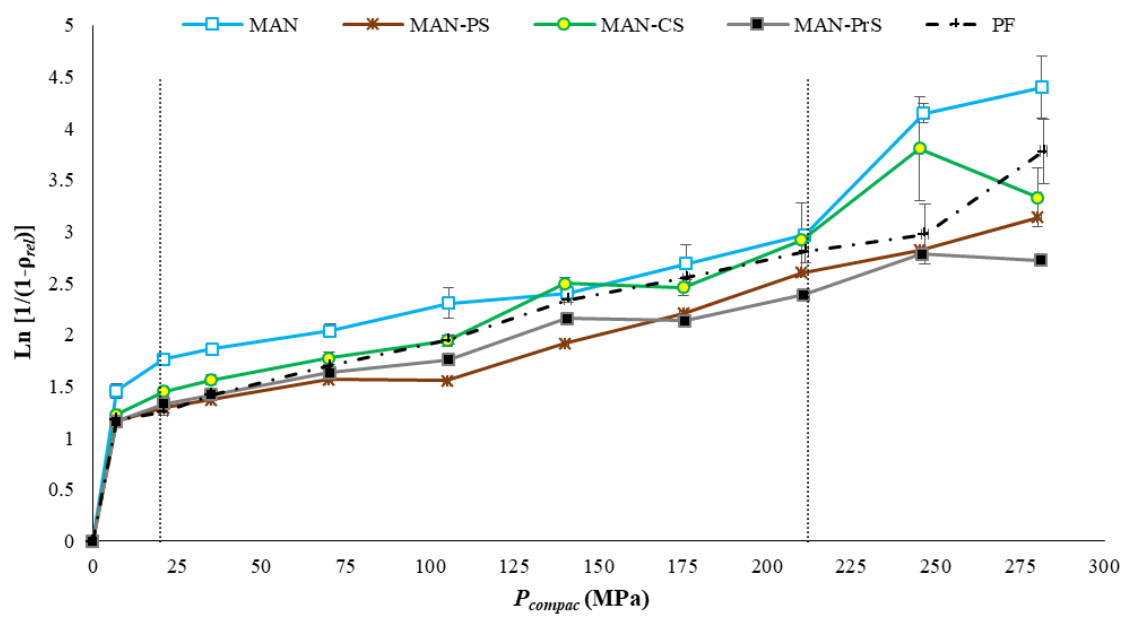

a)

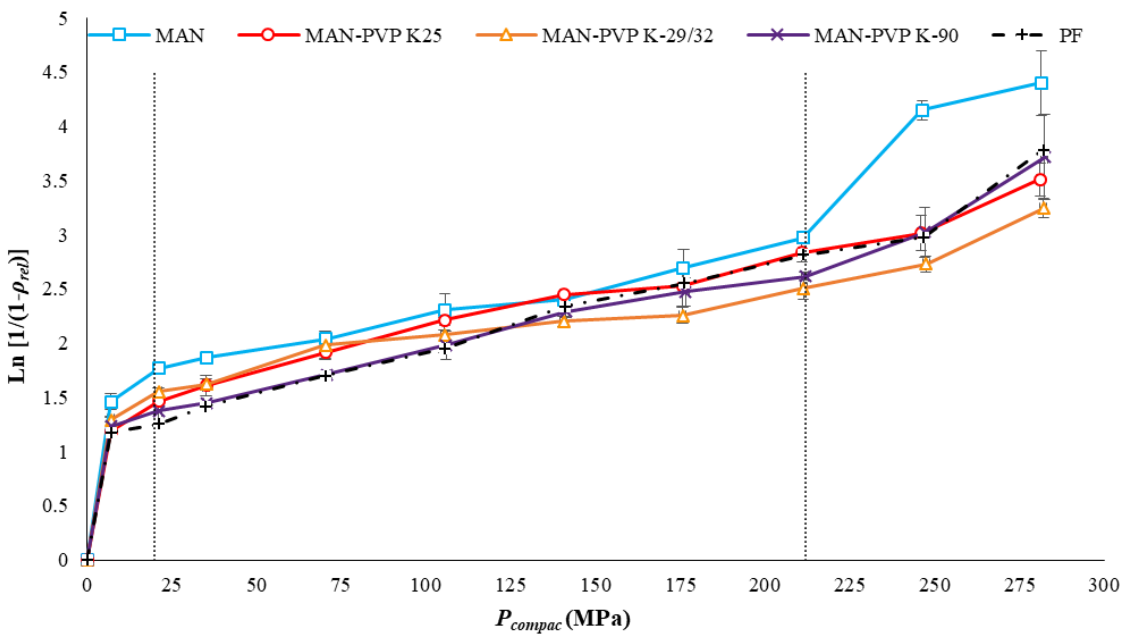

Figure 2.

Heckel plots of mannitol and co-processed excipients: a) starches and b) povidones

Even though some authors have reported deviations of Heckel modelling from linearity at lower compaction pressures (0 - 50 MPa) [44], in our data the linearity was observed with the range mentioned before; such region is shown between the dotted vertical lines in Heckel plots. The slope of the plots represents the Heckel constant $(K)$, and its reciprocal, $P_{y}$ gives information related with the plastic behaviour of a material; it represents the stress at which plastic deformation of a particle occurs [45]. The higher the $P_{y}$ value, the greater compaction pressure a material will need to form a tablet. Mannitol presented a $P_{y}$ of $180.80 \mathrm{MPa}$, a relatively high value that explains its poor compressibility properties, an increased resistance to deformation due to either a brittle deforming mechanism or a decreased plastic flow. However, the co-processing procedure decreased the $P_{y}$ value in all the materials (except for MAN-PVP K-29/32), which means that co-processing allowed an increase in the plasticity of our materials compared with mannitol as the base excipient. MAN-CS presented the lower $P_{y}$ value (123.84 MPa, Figure 2a), while the material with PVP K-25 that had the best rheological properties has a $P_{y}$ of $142.63 \mathrm{MPa}$ (Figure 2b). Since Heckel data exhibited a normal distribution, the statistical analysis (Dunnett by multiple comparisons followed by an ANOVA) showed a statistically significant difference in $P_{y}$ (for all the co-processed materials with exception of MAN-PVP K-29/32) and $A$ (only PVP K-29/32) which is related to the relative density. With respect to the densification process, a MANOVA analysis showed a statistically significant difference in all the materials in comparison with mannitol alone. Pearlitol ${ }^{\circledR}$ Flash showed a densification behaviour like MAN-CS and their $P_{y}$ values were near one to another. 
Table III

Parameters of Heckel equation for mannitol and co-processed excipients

\begin{tabular}{|c|c|c|c|c|c|c|c|c|}
\hline Material & $K\left(\times 10^{-3}\right)$ & $P_{y}$ (MPa) & $A$ & $r^{2}$ & $P^{a}$ & $P^{b}$ & $P^{c}$ & $P^{d}$ \\
\hline MAN & $5.59 \pm 2.52 \times 10^{-4}$ & $180.80 \pm 6.67$ & $1.2259 \pm 0.04$ & 0.9893 & Control & Control & Control & Control \\
\hline MAN-PS & $7.26 \pm 2.54 \times 10^{-4}$ & $139.08 \pm 4.92$ & $1.0859 \pm 0.10$ & 0.9548 & $0.012 *$ & $0.012 *$ & $\begin{array}{c}0.078 \\
(\mathrm{NS})\end{array}$ & $0.000 *$ \\
\hline MAN-CS & $8.10 \pm 1.5 \times 10^{-3}$ & $123.84 \pm 22.56$ & $1.2200 \pm 0.11$ & 0.9803 & $\begin{array}{c}0.061 \\
\text { (NS) }\end{array}$ & $0.001 *$ & $\begin{array}{l}1.000 \\
\text { (NS) }\end{array}$ & $0.000 *$ \\
\hline MAN-PrS & $7.66 \pm 7.11 \times 10^{-4}$ & $130.54 \pm 24.93$ & $1.2849 \pm 0.05$ & 0.9672 & $\begin{array}{l}0.275 \\
\text { (NS) }\end{array}$ & $0.002 *$ & $\begin{array}{l}0.772 \\
\text { (NS) }\end{array}$ & $0.000 *$ \\
\hline MAN-PVP K-25 & $7.18 \pm 5.19 \times 10^{-4}$ & $142.63 \pm 10.00$ & $1.3661 \pm 0.03$ & 0.9833 & $\begin{array}{l}0.264 \\
(\mathrm{NS})\end{array}$ & $0.012 *$ & $\begin{array}{l}0.077 \\
\text { (NS) }\end{array}$ & $0.000 *$ \\
\hline MAN-PVP K-29/32 & $5.56 \pm 2.10 \times 10^{-4}$ & $179.85 \pm 8.89$ & $1.4426 \pm 0.01$ & 0.9445 & $\begin{array}{c}0.833 \\
\text { (NS) }\end{array}$ & $\begin{array}{l}1.000 \\
\text { (NS) }\end{array}$ & $0.000 *$ & $0.000^{*}$ \\
\hline MAN-PVP K-90 & $7.10 \pm 4.58 \times 10^{-4}$ & $140.81 \pm 9.95$ & $1.2173 \pm 0.03$ & 0.9921 & $\begin{array}{c}0.549 \\
\text { (NS) }\end{array}$ & $0.032 *$ & $\begin{array}{l}1.000 \\
\text { (NS) }\end{array}$ & $0.000 *$ \\
\hline Pearlitol ${ }^{\circledR}$ Flash (PF) & $7.81 \pm 5.97 \times 10^{-4}$ & $127.92 \pm 9.68$ & $1.1390 \pm 0.05$ & 0.9938 & $0.025^{*}$ & $0.001^{*}$ & $\begin{array}{c}0.369 \\
(\mathrm{NS})\end{array}$ & $0.000 *$ \\
\hline
\end{tabular}

$\mathrm{K}=$ Heckel constant; $\mathrm{P}^{\mathrm{a}}=\mathrm{P}$ value for Heckel constant $(\mathrm{K}) ; \mathrm{P}^{\mathrm{b}}=\mathrm{P}$ value for Yield pressure; $\mathrm{P}^{\mathrm{c}}=\mathrm{P}$ value for $\mathrm{A}\left(\rho_{\text {rel }}=1-\mathrm{e}^{-\mathrm{A}}\right) ; \mathrm{P}^{\mathrm{d}}=\mathrm{P}$ value for densification process by MANOVA analysis; * = statistically different to mannitol alone when $\alpha \leq 0.05$; NS = not significant

Nordström et al. [46] reported that the mechanism of deformation for mannitol with a similar particle size to the used in this research, involved the fracture, but in such investigation the $P_{y}$ value was $132 \mathrm{MPa}$, while other authors reported that mannitol is a plastic or ductile material as microcrystalline cellulose is [21]. This feature could be attributable to the existence of polymorphs; Burger et al. reported an induction of the polymorphic transition from $\beta$ to $\delta$ mannitol, resulting in an enhancement of compressibility and compactibility of the material due to an increment in its density and a reduction of the elastic recovery during decompression [19]. In accordance with the classification of Roberts \& Rowe [47], all the materials are classified in terms of their plasticity as moderately hard materials since their $P_{y}$ values were between 80 and $200 \mathrm{MPa}$ and we rank-ordered them as following: Mannitol-Corn Starch > Mannitol-Pregelatinized Starch > Mannitol-Potato starch > Mannitol-Povidone K-90 > Mannitol-Povidone K-25 >> MannitolPovidone K-29/32 >> Mannitol (base excipient).

An explanation for the $P_{y}$ reduction in those materials with potato starch, corn starch, and pregelatinized starch could be the plasticity of starches in addition to their moisture content and even a synergistic effect. It is well known that water provides a plastic and lubricant effect [42, 48]; while in case of the materials with PVP K-25 and K-90, it has been reported for polymers like PVP and HPMC that moisture acts as a plasticizer by decreasing their $T_{g}$, then the material undergoes a transformation from a glassy to a rubbery state in which polymers have higher compression and compaction properties [49]. Additionally, water also fills the materials' pores and therefore helps to reduce the porosity [50]. Patel et al. found a strong dependence of $P_{y}$ value on particle size of paracetamol, where increasing particle size resulted in higher yield pressure values, the increment in $P_{y}$ for MAN-PVP K-29/32 could be influenced with size and shape of the particles in comparison with the PVP $\mathrm{K}-25$ co-processed material [51].

Heckel model evaluates the effect of compaction pressure on densification or reduction of porosity during compression and has been used to assess the deformation mechanism of single compounds, and binary and ternary mixtures $[52,53]$. This model is still widely used despite being questioned in the literature because of the obtained value parameters differ from one author to another depending on accuracy and robustness of the model $[54,55]$.

Tensile strength plots

Several investigations and models have been conducted and studied to gain knowledge about the mechanical properties of tablets [56-60]; however, the relationship of mechanical properties at different scale is not yet entirely understood [61]. During compaction process, measurements can be realized to ensure that compacts will have mechanical strength enough to avoid their abrasion and breaking when are being processed and handled; therefore, during manufacturing two tests are used to evaluate the mechanical strength of tablets: friability and resistance to crushing strength through diametrical tensile strength. The last one is the most used due to its easier implementation.

Figure 3 shows $\sigma_{T}$ as a function of $P_{\text {compac }}$ plots. It is noticed from these plots that tablets of mannitol did not increase their mechanical strength despite variations in compaction pressure, and even a decrease in tablet resistance is observed and attributable to an overcompaction, evidencing mannitol's poor compactibility reported by other authors [19, 41, 62]. For the coprocessed materials containing starch (potato, corn and pregelatinized) it was observed a 3-6 times increment in the mechanical strength of the tablets compared to the base excipient in the range 7-175 MPa (Figure 3a). 


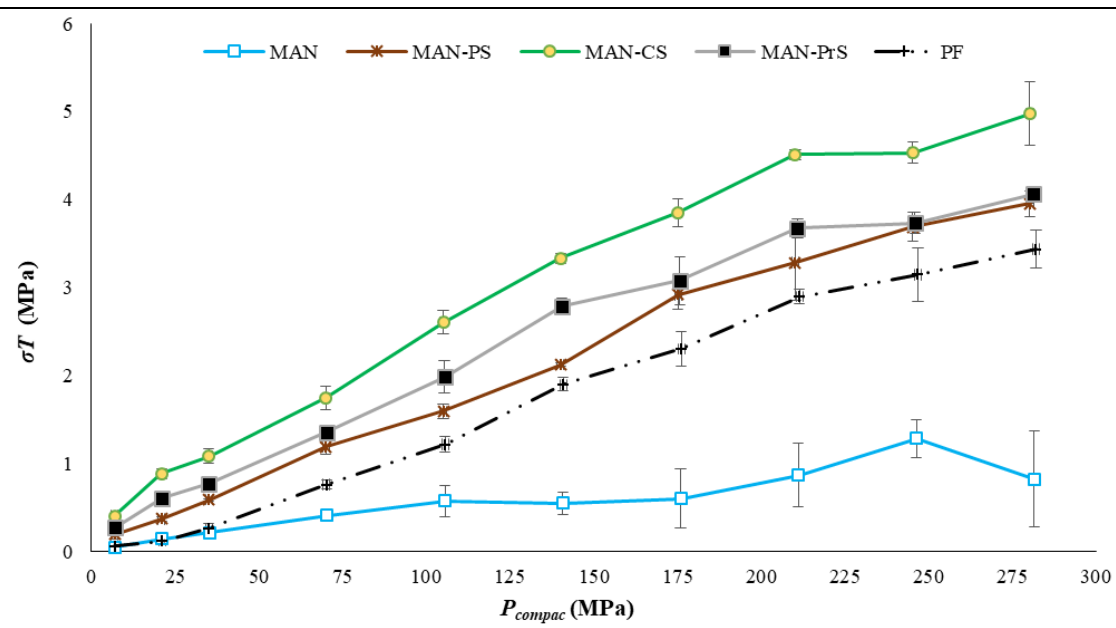

a)

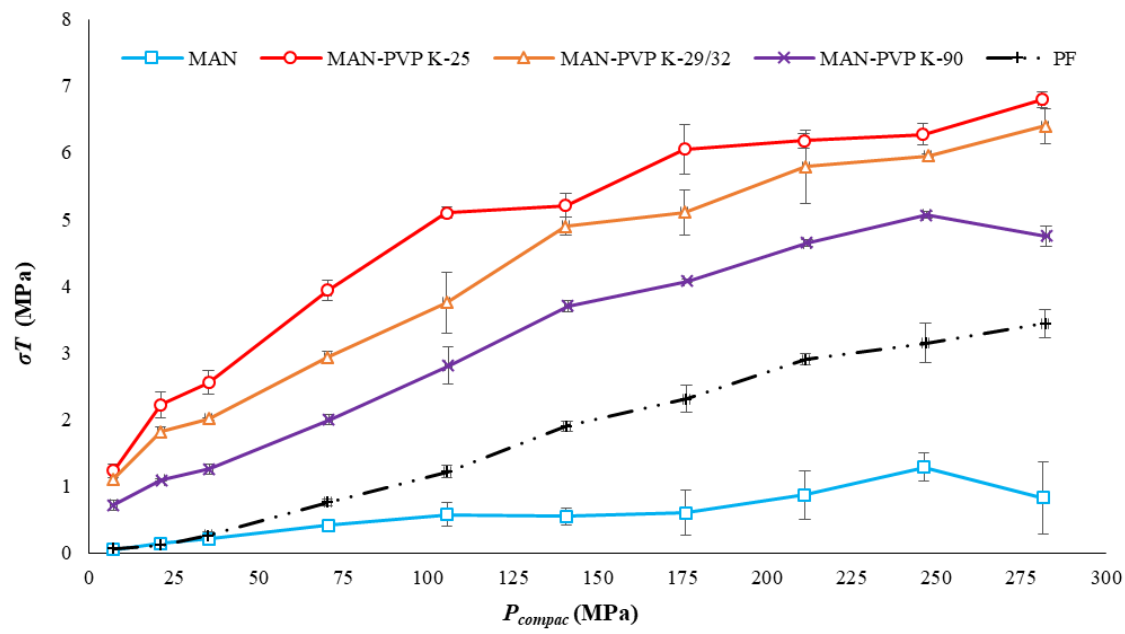

Figure 3.

Tensile strength as function on compaction pressure plots of mannitol, commercial product (Pearlitol ${ }^{\circledR}$ Flash, PF) co-processed excipients: a) starches and b) povidones

In the case of the co-processed containing PVP K-25 and K-29/32, a 10 times enhancement of mechanical strength of tablets was observed compared with mannitol alone for the same range of compaction pressures. The material with PVP K-90 was intermediate to the other materials (Figure $3 b$ ), while Pearlitol ${ }^{\circledR}$ Flash showed an inferior mechanical resistance in comparison with all our materials.

Powder consolidation in tablets is a process that involves pores reduction in the materials while interparticulate bonds are created, which in turn implies different stages [63]. During compression process, there are two related events: compressibility, defined as the ability of a powder to reduce its volume under a pressure (represented by a porosity or densification $v s$. compaction pressure plot), and compactibility, defined as the ability of a powder to form a tablet with a mechanical hardness (represented by a tensile strength $v s$. compaction pressure plot) [64]. Some authors define compactability as the ability of a material to be transformed into tablets with certain hardness during the densification process and represent it by a tensile strength $v s$. solid fraction plot, considering such property as the most valuable. In addition, they consider a third property, the tablet ability represented by the definition of Leuenberger \& Rohera to compactibility (tensile strength $v s$. compaction pressure plot) [64, 65].

Ryshkewitch-Duckworth model

The Ryshkewitch-Duckworth is an empiric model designed for the study of ceramic materials such as alumina and zirconia to study the relationship between mechanical strength and porosity and has been used to study several materials considering the porosity or the solid fraction [66]. It was found that the logarithm of the tensile strength is inversely proportional to the porosity and later, Duckworth made a correlation for a single compound tablets that resulted in equation 10 [67]. Such equation has been successfully applied to different systems with pharmaceutical applications and other science disciplines [68]. Since our materials were designed to be used as carriers in direct compression, we are considering these co-processed excipients as a single component excipient since they were granulated.

The effect of porosity on tensile strength is depicted in Figure 4 for mannitol and its co-processed excipients. Clearly can be seen that mannitol alone had a very 
low mechanical strength independently of its porosity. For all the co-processed excipients (Figure 4a for starches' and Figure 4b for povidones' co-processed excipients), can be observed that with decreasing the porosity, the higher mechanical strength tablets are produced, being the best co-processed materials MAN-PrS and MAN-PVP K-25.

a)
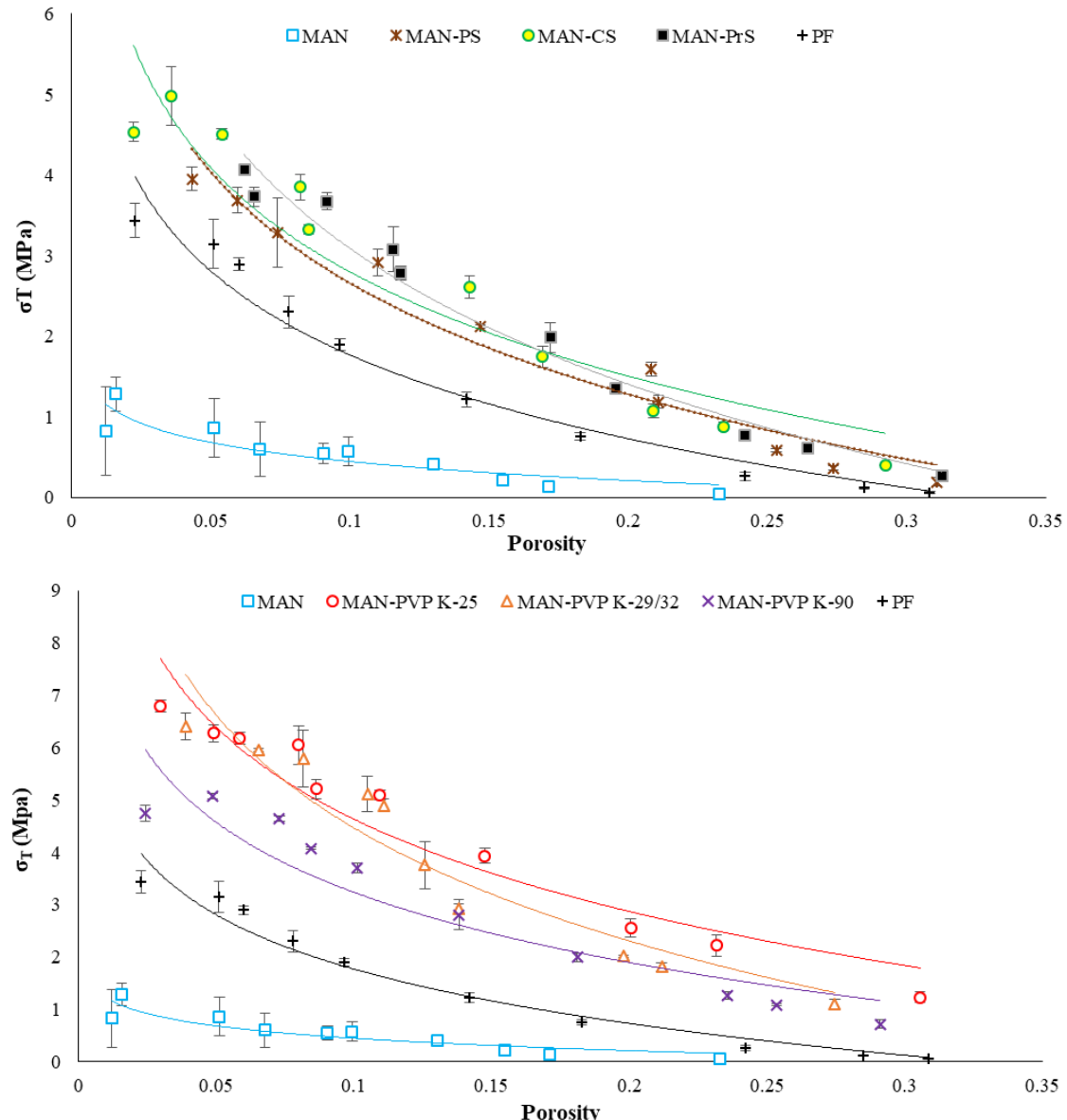

Figure 4.

Tensile strength plots as function of porosity of mannitol, commercial product (Pearlitol ${ }^{\circledR}$ Flash, PF) and coprocessed excipients: a) starches and b) povidones

All the correlation coefficients obtained by linear regression are higher than 0.95 , with exception of mannitol, which demonstrates that the relationship between the logarithm of the tensile strength and the porosity is linear and the experimental data can be fitted by Ryshkewitch-Duckworth equation. In the model, $k$ represents the bonding capacity and $\sigma_{T O}$ the tensile strength at zero porosity; the highest the $k$ value, the stronger bonding of primary particles will be. The values of such parameters are presented in Table IV. Co-processed materials with PVP K29/32 and PVP K-25 have the highest tensile strength at zero porosity, followed by that one with pregelatinized starch; however, mannitol alone had the highest bonding capacity and its value was close to the obtained by Pearlitol ${ }^{\circledR}$ flash and the reported value by Reynolds et al. (12.40 MPa), even though they used a mannitol for direct compression (Pearlitol ${ }^{\circledR}$ 200SD) [69]. This means that materials with PVP
K-29/32, PVP K-25 and pregelatinized starch could produce strong tablets, and decreasing too much their porosity will increase the tensile strength; the bonding capacity for the materials with PVP K-25 and K29/32 (6.04 and 6.92 MPa respectively) was near to the MCC value reported by Wu et al., (7.6) [70]. In contrast, tablets produced with mannitol alone will have very low tensile strength and decreasing the porosity could not increase significantly their mechanical resistance. Kruskall-Wallis test showed a statistically significant difference of tensile strength at zero porosity in our materials with respect to mannitol alone, while a Dunnett followed by an ANOVA test proved a statistically significant difference for RhyshkewitchDuckworth constant with exception of MAN-PS and MAN-PrS. Finally, a MANOVA test showed that the profiles ( $\sigma$ To vs. $\varepsilon$ ) of our materials were statistically significant different to mannitol (Table IV). 
Table IV

Parameters of Ryshkewitch-Duckworth equation for mannitol and co-processed excipients

\begin{tabular}{lcccccc}
\hline \multicolumn{1}{c}{ Material } & $\boldsymbol{k}$ & $\boldsymbol{\sigma}_{\boldsymbol{T} \boldsymbol{0}}$ & $\boldsymbol{r}^{\mathbf{2}}$ & $\boldsymbol{P}^{\boldsymbol{a}}$ & $\boldsymbol{P}^{\boldsymbol{b}}$ & $\boldsymbol{P}^{\boldsymbol{c}}$ \\
\hline MAN & $13.21 \pm 1.24$ & $1.71 \pm 0.36$ & 0.9368 & Control & Control & Control $^{-}$ \\
\hline MAN-PS & $9.79 \pm 0.40$ & $7.87 \pm 0.42$ & 0.9879 & $\begin{array}{c}0.474 \\
(\mathrm{NS})\end{array}$ & 0.000 & $0.000^{*}$ \\
\hline MAN-CS & $8.28 \pm 0.36$ & $6.79 \pm 0.30$ & 0.9725 & $0.001^{*}$ & 0.000 & $0.000^{*}$ \\
\hline MAN-PrS & $9.68 \pm 0.32$ & $8.63 \pm 0.16$ & 0.9701 & 0.354 & 0.000 & $0.000^{*}$ \\
MAN-PVP K-25 & $6.04 \pm 0.24$ & $9.09 \pm 0.35$ & 0.9768 & $0.000^{*}$ & 0.000 & $0.000^{*}$ \\
\hline MAN-PVP K-29/32 & $6.92 \pm 0.45$ & $11.65 \pm 0.74$ & 0.9622 & $0.000^{*}$ & 0.000 & $0.000^{*}$ \\
\hline MAN-PVP K-90 & $7.73 \pm 0.23$ & $7.89 \pm 0.26$ & 0.9963 & $0.000^{*}$ & 0.000 & $0.000^{*}$ \\
\hline Pearlitol ${ }^{\circledR}$ Flash (PF) & $13.62 \pm 0.77$ & $7.04 \pm 0.49$ & 0.9832 & $0.000^{*}$ & 0.000 & $0.000^{*}$ \\
\hline
\end{tabular}

$\mathrm{k}=$ bonding capacity or Ryshkewitch-Duckworth constant; $\sigma_{\mathrm{T} 0}=$ tensile strength at zero porosity; $\mathrm{P}^{\mathrm{a}}=\mathrm{P}$ value for Bonding capacity constant $(\mathrm{k}) ; \mathrm{P}^{\mathrm{b}}=\mathrm{P}$ value for $\sigma_{\mathrm{T} 0} ; \mathrm{P}^{\mathrm{b}}=\mathrm{P}$ value for porosity reduction by MANOVA analysis; $*$ statistically different to mannitol alone when $\alpha \leq$ $0.05 ; \mathrm{NS}=$ not significant

Despite that Ryshkewitch-Duckworth was an empirical model, according to Kundsen and Andersson there is a theoretical explanation related with the particle size, bond surface area between particles, pore shapes and even their orientation over the particles [71, 72]. Vromans et al., studied the correlation of the tensile strength with the surface area of lactose blends that was determined by mercury porosimetry. They found that the tensile strength was proportional to the surface area [73], while De Boer et al., also found a correlation of the tensile strength with the particle size at different compaction pressures, the smaller the particle size was, the higher the surface area in contact between particles and so the tensile strength [74]. On the other hand, some studies also considered the effect of the shape of the particles of some materials in their tensile

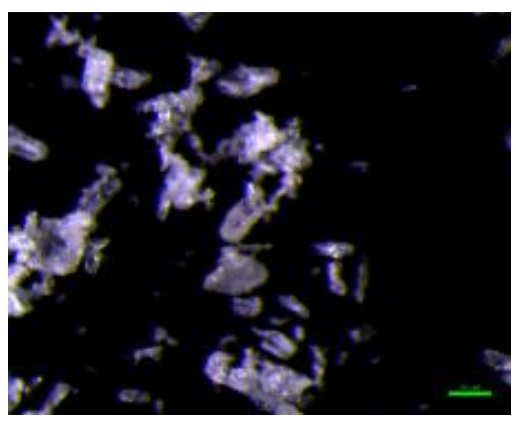

a)

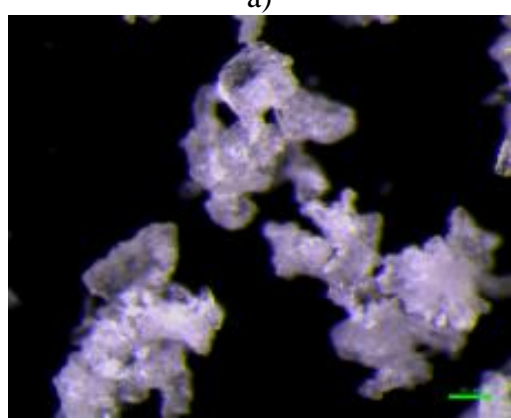

c) strength and found that such property increased when more irregular the particles were, even in comparison with spherical particles [75, 76]. Is widely known that different grades of polymerization of PVP result in various molecular weights, conform they increase, the $\mathrm{K}$ value does as well and so their viscosity in aqueous solution resulting in harder granules. Wet granulations with PVP K-25/30/90 generally produces granules with better flow properties in comparison with other binders and gives higher binding strength when its concentration increases [77, 78]. In comparison, use of starches as binders produces granules that tend to adsorb and absorb water that does not allow them to establish strong interactions between particles leading to softer tablets with higher friability [77].

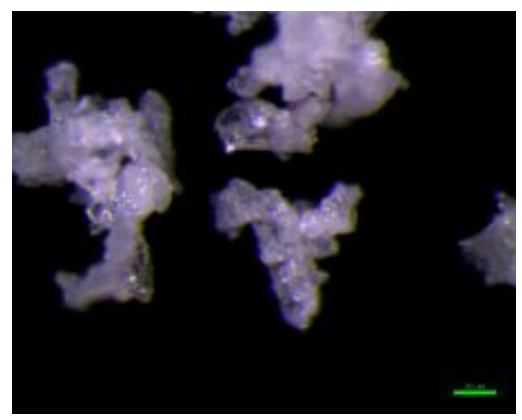

b)

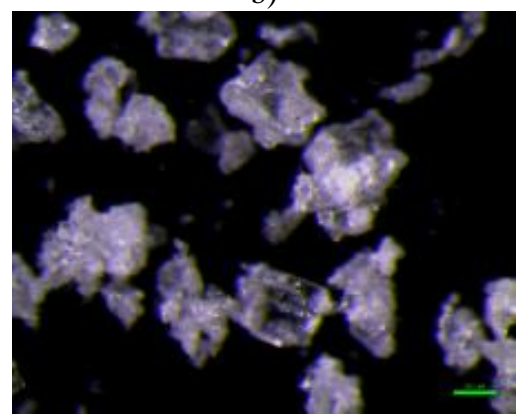

d)

Figure 5.

Microphotographs at 56 X for: a) primary particles of mannitol, b) MAN-PVP K-25, c) PVP K-29/32 and d) MAN-PrS 
The micrographics of mannitol and the co-processed excipients with PVP K-25, PVP K-29/32, and pregelatinized starch are presented in Figure 5, in which the primary particles of mannitol can be observed (5a) that seem to be crystalline structures; while in the co-processed excipients (5b-d), irregular particles are seen. Particle-particle bonding during compaction depends not only on factors like physical interactions related to the surface, size and shape of the particles, but also in molecular interactions (interfacial forces), and it has been proved that the magnitude of the attraction forces is highly influenced by the pressure applied and the surface energy [79]. The last one is closely related with the porosity of the materials, and in addition to the roughness of the particles in our coprocessed excipients, could promote the mechanical interlocking among particles, resulting in the increase of the tensile strength of such materials.

\section{Conclusions}

This study shows how the wet granulation in a fluid bed drier as a co-processing methodology can improve the bad flow, compressibility and compactibility properties of crystalline mannitol in combination with different polymers. The rheological characterization of mannitol and the co-processed excipients exhibited an improvement in the flow and compressibility properties of our materials with respect to mannitol alone, showing that the best materials were those produced with povidone K-25 and pregelatinized starch. Compressibility characterization by Heckel modelling demonstrated an improvement in the densification process and decrease in yield pressure values for such materials too, which since a technological point of view is very important since it could represent either a lesser tooling weathering or producing tablets with lower compaction pressures. Tablet ability profiles and compactibility by Ryshkewitch-Duckworth modelling exhibited how the relationship between tensile strength with compaction pressure and solid fraction or porosity can be useful tools in order gain knowledge about the understanding of mechanical properties of materials when producing tablets; furthermore, they could provide support during tablet formulation, scale-up and technology transference, being the co-processed with povidone K-25 the material with better tensile strength independently of compaction pressure or porosity. Until now there are few reports about coprocessing of mannitol and just a few of them provide a characterization that gives information about performance of the materials at an industrial scale; moreover, none of such reports used the polymers and process under study in the present research.

According to the characterization performed, we can conclude that the materials with the best properties were MAN-PVP K-25 and MAN-PrS, which could be widely recommended to be used in direct compression.

\section{Acknowledgement}

Oswaldo Castañeda Hernández is a master student from Maestría en Ciencias Farmacéuticas, Universidad Autónoma Metropolitana (UAM) and received fellowship 354618 from National Council for Sciences and Technology (CONACYT).

\section{References}

1. Villanova J, Ayres E, Oréfice R, Design of prolonged release tablets using new solid acrylic excipients for direct compression. Eur J Pharm Biopharm., 2011; 79: 664-673.

2. Augsburger L, Hoang S, Pharmaceutical dosage forms: Tablets Volume 2. $3^{\text {rd }}$ ed. New York (US): Informa Healthcare; 2008. Chapter 5, Direct compression and role of filler-binders: 173-216.

3. Augsburger L, Hoang S, Pharmaceutical dosage forms: Tablets Volume 1. $3^{\text {rd }}$ ed. New York (US): Informa Healthcare; 2008. Chapter 9, Dry granulation: 303-336.

4. Augsburger L, Hoang S, Pharmaceutical dosage forms: Tablets Volume 1. $3^{\text {rd }}$ ed. New York (US): Informa Healthcare; 2008. Chapter 8, Pharmaceutical granulation processes, mechanism, and the use of binders: 261-302.

5. Parikh D, Handbook of Pharmaceutical Granulation Technology. $2^{\text {nd }}$ ed. North Carolina (US): Taylor \& Francis; 2005. Chapter 1, Introduction: 1-19.

6. Rojas J, Aristizabal J, Henao M, Screening of several excipients for direct compression of tablets: A new perspective based on functional properties. Rev Ciênc Farm Básica Apl., 2013; 34(1): 17-23.

7. Gohel M, Jogani P, A review of co-processed directly compressible excipients. J Pharm \& Pharm Sci., 2005; 8(1): 76-93.

8. Daraghmeh N, Rashid I, Al Omari M, Leharne SA, Chowdhry BZ, Badwan A, Preparation and characterization of a novel co-processed excipient of chitin and crystalline mannitol. AAPS Pharm SciTech., 2010; 11(4): 1558-1571.

9. Mirani A, Patankar S, Borole V, Pawar AS, Kadam VJ, Direct Compression High Functionality Excipient Using Coprocessing Technique: A Brief Review. Curr Drug Deliv., 2011; 8(4): 426-435.

10. Chaudari P, Phatak A, Desai U, A review: Coprocessed excipients-an alternative to novel chemical entities. Int J Pharm Chem Sci., 2012; 1(4): 1480-1498.

11. Villafuerte R, Los excipientes y su funcionalidad en productos farmacéuticos sólidos, Rev Mex Cienc Farm., 2011; 42(1): 18-36.

12. Rowe R, Sheskey P, Quinn M, Handbook of pharmaceutical excipients. $6^{\text {th }}$ ed. London (UK): Pharmaceutical Press; 2009: 424-428.

13. Nadavadekar P, Koliyote S, Co-processed Excipients for Orally Disintegrating Dosage Form. Int J Pharm Res Rev., 2014; 3(4): 95-100.

14. Lee Y, Wu J, Yang M, Young PM, van den Berg F, Rantanen J, Particle size dependence of polymorphism in spray-dried mannitol. Eur J Pharm Sci., 2011; 44: 41-48. 
FARMACIA, 2019, Vol. 67, 6

15. Pitkánen I, Perkkalainen P, Rautiainen H, Thermoanalytical studies on phases of D-Mannitol. Thermochim Acta, 1993; 214: 157-162.

16. Mehta M, Bhardwaj S, Suryanarayanan R, Controlling the physical form of mannitol in freeze-dried systems. Eur J Pharm Biopharm., 2013; 85: 207-213.

17. Cares M, Vaca G, Calvet R, Espitalier F, Letourneau JJ, Rouilly A, Rodier E, Physicochemical characterization of D-mannitol polymorphs: The challenging surface energy determination by inverse gas chromatography in the infinite dilution region. Int J Pharm., 2014; 475: 69-81.

18. Wagner C, Pein M, Breitkreutz J, Roll compaction of manitol: Compactibility study of crystalline and spraydried grades. Int J Pharm., 2013; 453: 416-422.

19. Burger A, Henck J, Hetz S, Rollinger JM, Weissnicht AA, Stöttner H, Energy/temperature diagram and compression behavior of the polymorphs of DMannitol. J Pharm Sci., 2000; 89(4): 457-468.

20. Wagner C, Pein M, Breitkreutz J, Roll compaction of granulated mannitol grades and the unprocessed crystalline delta-polymorph. Powd Tech., 2015; 270: 470-475.

21. Ohrem H, Schormick E, Kalivoda A, Ognibene R, Why is mannitol becoming more and more popular as a pharmaceutical excipient in solid dosage forms?. Pharm Dev Technol., 2014; 19(3): 257-262.

22. Adeoye O, Alebiowu G, Flow, packing and compaction properties of novel co-processed multifunctional directly compressible excipients prepared from tapioca starch and mannitol. Pharm Dev Technol., 2014; 19(8): 901-910.

23. Bouffard J, Kaster M, Dumont H, Influence of process variable and physicochemical properties on the granulation mechanism of mannitol in a fluid bed top spray granulator. Drug Dev Ind Pharm., 2005; 31: 923-933.

24. Gonnissen Y, Verhoeven E, Peters E, Remon JP, Vervaet $\mathrm{C}$, Coprocessing via spray drying as a formulation platform to improve the compactibility of various drugs. Eur J Pharm Biopharm., 2008; 69: 320-334.

25. Gonnissen Y, Vieira S, Remon J, Mixture design applied to optimize a directly compressible powder produced via cospray drying. Drug Dev Ind Pharm., 2008; 34: 248-257.

26. Ramírez M, García M, Piña J, Palma S, Allemandi D, Bucalá V. (2013). Patent number WO 2013175405 A1, Co-processed excipient, obtained by spraydrying, usable as a pharmaceutical excipient or food additive.

27. United States Pharmacopeia, National Formulary 37, 2014. <786> Particle Size Distribution Estimation by Analytical Sieving, 394-398.

28. United States Pharmacopeia, National Formulary 37, 2014. <616> Bulk density and tapped density of powders, 298-301.

29. Fell J, Newton J, The tensile strength of lactose tablets. J Pharm Pharmacol., 1968; 20(8): 657-659.

30. Lahdenpää E, Niskanen M, Yliruusi J, Crushing strength, disintegration time and weigh variation of tablets compressed from three Avicel ${ }^{\circledR} \mathrm{PH}$ grades and their mixtures. Eur J Pharm Biopharm., 1997; 43: 315-322.
31. Kushner J, Utilizing quantitative certificate of analysis data to assess the amount of excipient lot-to-lot variability sampled during drug product development. Pharm Dev Technol., 2013; 18(2): 333-342.

32. Hlinak A, Kuriyan K, Morris K, Reklaitis VG, Basu PK, Understanding critical material properties for solid dosage form design. J Pharm Innov., 2006, 1: 12-17.

33. Aulton M, Taylor K, Aulton's Pharmaceutics: The Design and Manufacture of Medicines. $4^{\text {th }}$ ed. Edinburgh (UK): Churchill Livingstone; 2013. Chapter 28, Powders, granules and granulation: 466-486.

34. Qiu Y, Chen Y, Zang G, Liu L, Porter W, Developing Solid Oral Dosage Forms. $1^{\text {st }}$ ed. London (UK): Academic Press; 2009. Chapter 8, Particle, powder, and compact characterization: 163-186.

35. United States Pharmacopeia, National Formulary 37, 2014. <1174> Powder flow, 1051-1054.

36. Bagster R, Crooks M, Flow studies on directly compressible Tablet vehicles. Drug Dev Ind Pharm., 1977; 3(5): 475-487.

37. Nelson E, Measurement of the repose angle of a Tablet granulation. J Am Pharm Assoc., 1955; 44(7): 435-437.

38. Ofori K, Amanor K, Lugrie S., Kuntworbe N, El Boakye-Gyasi M, Development and evaluation of natural gum-based extended release matrix tablets of two model drugs of different water solubilities by direct compression. Saudi Pharm J., 2016; 24: 82-91.

39. Schuzle D, Powders and Bulk Solids Behaviour, Characterization, Storage and Flow. $1^{\text {st }}$ ed. Berlin, Germany: Springer; 2008. Chapter 6, Discussion of testers and test procedures: 163-198.

40. Hiestand E, Powders: Particle-particle interactions. J Pharm Sci., 1996; 55(12): 1325-1344.

41. Katsuno E, Tahara K, Takeuchi Y, Takeuchi H, Orally disintegrating tablets prepared by a co-processed mixture of micronized crospovidone and mannitol using a ball mill to improve compactibility and tablet stability. Powd Tech., 2013; 241: 60-66.

42. Nokhodchi A, Ford J, Rowe P, Rubinstein MH, The influence of moisture content on the consolidation properties of Hydroxypropylmethylcellulose K4M (HPMC 2208). J Pharm Pharmacol., 1996; 48: 1116-1121.

43. Comoglu T, An overview of compaction equations. J Fac Pharm Ankara, 2007; 36(2): 123-133.

44. Denny P, Compaction equations: a comparison of the Heckel and Kawakita equations. Powd Tech., 2002; 127(2): 162-172.

45. Fung S, Adams M, Seville J, Zhang Z, Single and bulk compression of pharmaceutical excipients: Evaluation of mechanical properties. Powd Tech., 2008; 185: 1-10.

46. Nordström J, Klevan I, Alderborn G, A protocol for the classification of powder compression characteristics. Eur J Pharm Biopharm., 2012; 80: 209-216.

47. Roberts R, Rowe R, The compaction of pharmaceutical and other model materials - a pragmatic approach. Chem Engin Sci., 1987; 42: 903-911.

48. Steendam R, Frijlink H, Lerk C, Plasticisation of amylodextrin by moisture. Consequences for compaction behaviour and tablet properties. Eur J Pharm Sci., 2001; 14: 245-254. 
49. Oksanen $\mathrm{C}$, Zografi $\mathrm{G}$, The relationship between the glass transition temperature and water vapor absorption by Poly(vinylpyrrolidone). Pharm Res., 1990; 7(6): 654-657.

50. Zografi G, Kontny M, The interactions of water with cellulose- and starch-derived pharmaceutical excipients. Pharm Res., 1986; 3(4): 187-194.

51. Patel S, Kaushal A, Bansal A, Effect of particle size and compression force on compaction behavior and derived mathematical parameters of compressibility. Pharm Res., 2007; 24: 111-124.

52. Ikka J, Paronen P, Prediction of the compression behaviour of powder mixtures by the Heckel equation. Int J Pharm., 1993; 94: 181-187.

53. Ili'c I, Kása P, Dreu R, Pintye-Hódi K, Srcic S, The compressibility and compactibility of different types of lactose. Drug Dev Ind Pharm., 2009; 35(10): 1271-1280.

54. Ili'c I, Govedarica B, Sibanc R, Dreu R, Srčič S, Deformation properties of pharmaceutical excipients determined using an in-die and out-die method. Int J Pharm., 2013; 446: 6-15.

55. Sonnergaard J, A critical evaluation of the Heckel equation. Int J Pharm., 1999; 193: 63-71.

56. Frenning G, Nordström J, Alderborn G, Effective Kawakita parameters for binary mixtures. Powd Tech., 2009; 189: 270-275.

57. Aryanpour G, Farzaneh M, Application of a piston equation to describe die compaction of powders. Powd Tech., 2015; 277: 120-125.

58. Yap S, Adams M, Seville J, Zhang Zhibing, Single bulk compression of pharmaceutical excipients: Evaluation of mechanical properties. Powd Tech., 2015; 185: 1-10.

59. Kuentz M, Leuenberger H, A new theoretical approach to tablet strength of a binary mixture consisting of a well and a poorly compactable substance. Eur $J$ Pharm Biopharm., 2000; 49: 151-159.

60. Podczeck F, Methods for the practical determination of the mechanical strength of tablets-From empiricism to science. Int J Pharm., 2012; 436: 214-232.

61. Juban A, Nouguier C, Briancon S, Hoc T, Puel F, Predictive model for tensile strength of pharmaceutical tablets based on local hardness measurements. Int $J$ Pharm., 2015; 490: 438-445.

62. Yoshinari T, Forbes R, York P, Kawashima Y, The improved compaction properties of mannitol after a moisture-induced polymorphic transition. Int J Pharm., 2003; 258: 121-131.

63. Leuenberger H, Rohera B, Fundamentals of powder compression. I. The compactibility and compressibility of Pharmaceutical powders. Pharm Res., 1986; 3(1): 12-22.

64. Leuenberger $\mathrm{H}$, The compressibility and compactibility of powder systems. Int J Pharm., 1982; 12: 41-55.

65. Kim C, Sun C, Amidon G, Evaluation of the effects of tableting speed on the relationships between compaction pressure, tablet tensile strength, and tablet solid fraction. J Pharm Sci., 2005; 94(3): 465-472.

66. Ryskewitch E, Compression strength of porous sintered alumina and zirconia. J Am Ceram Soc., 1953; 36(2): 65-68.

67. Duckworth W, Discussion of Ryshkewitch paper. $J$ Am Ceram Soc., 1953; 36(2): 68

68. Gutowski W, Recent advances in adhesion science and technology. In honor of Dr. Kash Mittal. $2^{\text {nd }}$ ed. Florida (US): CRC Press; 2014. Chapter 3: Particle adhesion in the pharmaceutical sciences: 41-66.

69. Reynolds G, Campbell J, Roberts R, A compressibility based model for predicting the tensile strength of directly compressed pharmaceutical powder mixtures. Int J Pharm., 2017; 531(1): 215-224.

70. Wu C, Best S, Bentham A, Hancock B, Bonfield W, Predicting the tensile strength of compacted multicomponent mixtures of pharmaceutical powders. Pharm Res., 2006; 23(8): 1898-1905.

71. Kundsen F, Dependence of mechanical strength of brittle polycrystalline specimens on porosity and grain size. J Am Ceram Soc., 1959; 42(8): 376-387.

72. Andersson C, Derivation of the exponential relation for the effect of ellipsoidal porosity on elastic modulus. J Am Ceram Soc., 1996; 79(8): 2181-2184.

73. Vromans H, De Boer H, Bolhuis G, Lerk CF, Kussendrager KD, Bosch H, Studies on tableting properties of lactose. Part 2. Consolidation and compaction of different types of crystalline lactose. Pharm Weekbl Sci., 1985; 7(5): 186-193.

74. De Boer H, Vromans H, Lerk C, Bolhuis GK, Kussendrager KD, Bosch $\mathrm{H}$, Studies on tableting properties on lactose. Part III. The consolidation behavior of sieve fractions of crystalline alphaLactose monohydrate. Pharm Weekbl Sci., 1986; 8(2): 145-150.

75. Poquillon D, Baco V, Talihades P, Andrieu E, Cold compaction of iron powders-relations between powder morphology and mechanical properties: Part II. Blending tests: results and analysis. Powd Tech., 2002; 126(1): 75-84.

76. Wong L, Pipel N, Effect of particle shape on the mixing of powders. J Pharm Pharmacol., 1990; 42(1): $1-6$.

77. Narang S, Badawy S, Handbook of pharmaceutical wet granulation, Theory and practice in a Quality by Design Paradigm, $1^{\text {st }}$ ed., London (UK): Elsevier. 2019. Chapter 9: Binders in wet granulation: 317349.

78. Okoye E, Kunle O, Ohwoavworhua F, Comparative study of some mechanical and release properties of paracetamol tablets formulated with cashew tree gum, povidone and gelatin as binders. Af J Biotech., 2009; 8(16): 3970-3973.

79. El Gindy N, Samaha M, Tensile strength of some pharmaceutical compacts and their relation to surface free energy. Int J Pharm., 1982; 13(1): 35-46. 